\title{
XXXIII. Analysis of the scammonies from Aleppo and Smyrna; to which are subjoined some observations on the red colour given to turnsole by the resins
}

\author{
Messr. Bouillon Lagrange \& Messr. Vogel
}

To cite this article: Messr. Bouillon Lagrange \& Messr. Vogel (1810) XXXIII. Analysis of the scammonies from Aleppo and Smyrna; to which are subjoined some observations on the red colour given to turnsole by the resins, Philosophical Magazine Series 1, 36:149, 181-186, DOI: 10.1080/14786441008563167

To link to this article: http://dx.doi.org/10.1080/14786441008563167

$$
\text { 曲 Published online: } 18 \text { May } 2009 .
$$

Submit your article to this journal ¿

\section{山ll Article views: 3}

Q View related articles ¿ 
From the very near approximation of the proportions between the sulphate of barytes and ammoniaco-magnesian phosphate, obtained in the analysis of all these products of sea water, to those which result from the decompusition of two equal quantities of sulphate of maonesia, it may be inferred that they contain no sulphate of soda*. For example, to decide whether the Scotch salt contains an alkaline sulphate, or not, J dissolved 1500 grains in a pint of boiling water, and evaporated till fourteen drachm measures only remained, the common salt being removed as soon as it was formed. The residuary liquid was divided into two equal portions, one of which gave 18 grains of sulphate of barytes, and the other, 14 grains of ammoniacomaynesian phosphate. The proportion between these numbers is so nearly that which has been alrcady assigned, (viz. 119 to 90,) that we may safely infer the total absence of sulphate of soda. This salt, indeed, is considered as incompatible with muriate of magnesia; but after digesting, for two or three days, 100 grains of the formoi, with 20 of the latter, evaporating to dryness, and washing the residuum with repeated afusions of alcoinol, I found that two grains of the muriate of magnesia had escaped decomposition.

Manchester, June 19, 1809.

XXXIII. Analysis of the Scammonies from Aleppo and Smyrna; to which are suljoined some Otservations on the red Colour given tn Turnsole by the Resins. By Messis. Boutlon Lagrange and Vugrlt.

$\mathrm{T}$ CHE two species of scammony in question are procured from the root of a plant which grows in Syria. It seems that it is by an incision made in the ront that the juice is extracted; each root yields about iwo drachms only. The juce thus extracted is dried $m$ the sun, and then exposed for sale: at least it is in this way that the fines and purest scammony is obtained. Frequent $l^{\text {, }}$, however, the in habitauts of Syria and Natolia, in order to procure a greater quantity of the sap, extract it by expression, not only from the root, but from the stalks and leaves: occagionally also they alulterate the scammony by mixing the juce procured from

* I employed more attention in investigatiag the presence of sulphate of soda in the produets of se water; because this salt is stated to be one of its ingredients by the Bishop of Llandaff, (Chemistry, vol. ii. p. 62,) and by other chemical writers.

+ Ainuir's de Chimie, tome lxxii. p. 69. 
it with that of some other milky and acrid plants, and sometimes they increase its weight by the addition of charcoal or other forcign substances. In order to ascertain that scammony does not contain any of these heterogeneous matters, we ought to break the pieces of the juice, and pick such as are brilliant within, rejecting those which appear too black, burnt, or sandy.

The scammony of Aleppo is light, of an ash gray, brilliant and transparent in its fracture. That of Smyrna is very compact, heavy, and of a deeper colour : it is also more difficult to reduce into powder than that of Aleppo.

Examination of the Scammony of Aleppo.-When the scammony is pure, it melts entirely on a plate of heated iron, and gives olit nauseous vapours: when pounded in water, the liquor is of a milky whiteness.

Boiling water makes it run into a mass. The liquor becomes ycllow, has a bitter taste, and is neither alkaline nor acid, which proves that this substance is not adulterated with ashes, as some authors assert.

Alcohol at 40 degrees forms a slight precipitate in this aqueous liquor, and with the acetate of lead we obtain yellowish thakes soluble in the nitric acid.

The alcoholic tincture of scammony is of a brownish yellow colour. This liquor reddens turnsole tincture : there remains, after the evaporation, a resin of a yellowish white and transparent.

This resin is entirely dissolved in the nitric acid, which is coloured yellow. The addition of water slightly disturbs the liquor.

This substance is equally soluble in a solution of pure potash, even cold, and the liquor acquires a yellow colour: if this solution be made with the help of heat, the colour is brown. Water even in great quantity does not precipitate resin. Even when saturated by the muriatic acid, it does not separate the resin. This triple compound of resin, acid, and potash, ought to excite the attention of practitioners : it would perhaps be possible in this way to find a solvent for resins which water does not affect.

That part of scammony which is insoluble in alcohol, when dried, acquired a gray colour.

When treated with boiling water, it coloured it yellow, and alcohol precipitated it in white flakes.

In order to determine the proportion of the constituent principles of the scammony of Aleppo, we took 100 parts of this substance, which we dissolved in alcohol : the liquor was coloured yellow. There remained, after the treatment 
by alcohol, a matter of a gray colour, which, when dried, weighed $0 \cdot 26$.

The alcoholic solution was evaporated to a syrupy consistence. Cold water precipitated from it a resin forming a homogeneous mass: the supernatant liquor was transparent and colourless. Evaporated to dryness, we obtained a brown matter soluble in water and in alcohol, forming a precipitate by the acetate of lead. This substance seems to be what is called the extractive matter : its weight was found to be 0.2 after having been dried.

The resinous mass separated and dried bad a yellow colour, and weighed 0.60 .

We afterwards treated the $0 \cdot 26$ of matter which was insoluble in alcobol, with boiling water. There remained after the evaporation a gluey matter, weighing $0 \cdot 3$, having all the characters of gum. The rest was merely the refuse of vegetable matter and a little silex.

The distillation of the scammony of Aleppo presented nothing remarkable. It gave as products, a very acid brown liquor and a light blackish oil. The charcoal resulting from the operation was black, brilliant, and compact; it contained carbonate of potash, carbonate of lime, alumine, silex, and a little iron.

Examination of the Scammony of Smyrna.-The fusion of the Smyrna scammony is less complete than that of Aleppo: instead of going into a mass with boiling water, it became knotty, and the water was dyed yellow. It is neither acid nor alkaline: the acetate of lead precipitates yellowish flakes from it.

100 parts of this scammony taken up by boiling alcohol, although less charged with resin, gave a deeper-coloured tincture than that which was made with Aleppo scammony. We obtained from the evaporation of the alcobol a brownish transparent resin, the weight of which was 0.28 . We found 0.66 of insoluble matter in the alcohol. This residue treated with boiling water coloured it yellow: it had a putrid sweetish taste, and alcohol precipitated from it Hakes soluble in water. The liquor evaporated left a thick gluey matter like mucilage, soluble in weak nitric acid when warm ; precipitating, on cooling, a white pulverulent matter which presented all the characters of mucous acid.

In this experiment, the water had only taken up 0.8 of the matter which was insoluble in the alcohol. The rest was submitted, with the help of heat, to the action of the nitric acid, which dissolves it with effervescence. AmM 4 monia 
monia added to this nitric solution formed a precipitate soluble in potash. The potash and the oxalate of ammonia also occasioned a precipitation. This residue is cumposed therefore of alumine and carbonate of lime, besides the refuse of vegctable matter, and that substance which is insoluble in water and in alcohol, a substance which seems to be oxygenated extract.

This substance incinerated left a whitish powder, soluble in a great measure, and with effervescence, in the muriatic acid. This solution contains alumine, lime, and a little iron. The portion not soluble in the muriatic acid, when treated by potash, gave a siliceous precipitate on the addition of an acid.

The water which had served to precipitate the resin, left, after the evaporation, a brown substance, weighing 0.5, of a bitter taste, attracting humidity from the atmosphere, soluble in alcohol, and abundantly precipitated from the aqueous solution by the acetate of lead. This substance presented all the properties of the extractive principle.

It results therefore from this analysis: 1st. That 100 parts of Aleppo scammony are thus constituted:

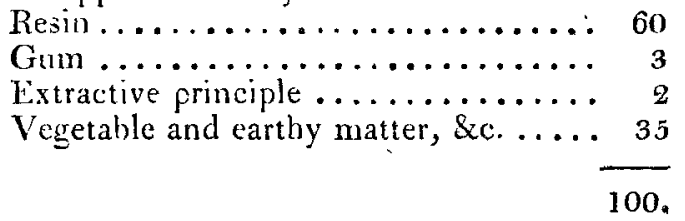

2. That Smyrna scammony contains :

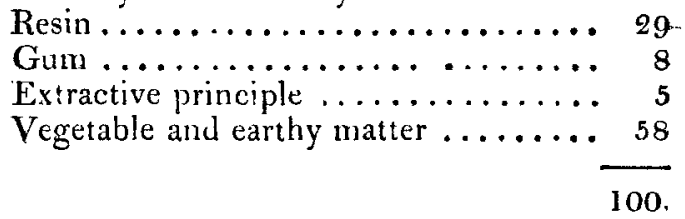

As the resin obtained from both kinds of scanmony is much the same, excepting that the Aleppo resin is yellow, transparent and friable, whereas that of Smyma is more highly coloured and more difficult to pulverise, we thought it would be useful to ascertain if there was any difference in their medicinal properties. Several physicians have since made experiments with both kinds on individuals of similar habits, and have observed no difference in point of purgative properties.

We may conclude therefore, from what precedes, that scammony is a true gum resin mixed with a little extractive 
matter. It contains indeed much less gum than the other gum resins, but enough, however, to form a milky liquid with water.

The action of the alcoholic tincture of scammony on turnsole, naturally led us to ascertain whether the property of reddening this blue colour was owing to an acid. Our experiments not having enabled us to acquire a direct pronf, we tried some resius in a comprarative manner, which we submitted to the following experiments.

1. Sandarach. This resin is converted into a knotty or grumous mass on being boiled with water. The flltered liquor remains clear: when properly evaporated, it slightly reddens turnsole tincture: the raste is bitter: it does not change the infusion of violets, is not precipitated by alcohol or by the acetate of lead; which proves that it contains neither gum nor extractive principle. It is therefore a prure resin.

The resin which had been treated with boiling water, was dissolved in alcohol. This liquor reddens turnsole tincture strongly, and has no action upon syrup of violets.

We also digested sandarach reduced into powder in alcohol, adding to the liquor, when warmed and filtered, boiling water, which precipitated the resin from it. The filtered liquor was turbid upon cooling. It had the strong smell of sandarach resin : its taste was bitter; and its action on turnsole tincture was so weak, that we could not presume the existence of a free acid.

2. Mdstich. This substance presents nearly the same phænomena with the above: the resin however runs into a mass in boiling water like turpentine. The water has a bitter taste, and has no action either upon turnsole or upon violet syrup. The resin, on the contrary, reddens turnsole tincture strongly.

3. Olibanum forms in hot water a thick magma, which is separated with difficulty from the liquor, even by filtration. This water has a blackish brown colour, is not precipitated by the acetate of lead, and does not change the colour of turnsole, but alcohol precipitates it in abundance; which proves that this substance is composed of gum and resin.

The alcoholic tincture reddens turnsole tincture strongly. If we carefully beat in a sand bath the resins which have most action on the colour of turnsole, no acid is sublimed.

When treated with lime according to Scheele's process, no calcareous benzoates are formed.

4. Ammoniacal gum resin, myrrh, gum elemi, galbanum, 
banum, tacamahaca, resin of common jalap, Venice turpentine, oil of turpentine, and several other resinous and gummo-resinous substances, gave the same results with those obtained from the scammonies, sandarach, and olibanum. From these facts we may infer that it is still difficult to resolve this question: Is it to the presence of an acid in the resins, that we ought to ascribe the reddening of turnsule?

If the acids alone had the property of reddening the blue vegetable colours, we should not hesitate in recognising the existence of this property in the resins, alt hough experiments have not yet proved it. As to the infusion of violets, over which the resins have no action, this property is found in the sublimated benzoic acid, which strongly reddens turnsole tincture, and which does not change the colour of violets. Has this acid, notwithstanding its solubility in water, any analogy to the resins? We shall abstain from deciding on this subject, although we are induced to believe that $t$ th sulstance is a compound of a vegetable acid, and a small quantity of resin, which perhaps gives it the concrete state: lastly, as all the vegetable acids are soluble in water, it is still difficult to ascribe to the presence of an acid, the property which resins have of reddening turnsole. It seems probable therefore, until some new experiments prove the contrary, that we may regard it as being one of the characters of the resins to redden the blue colour of turnsole.

XXXIV. On prime and ultimate Ratios; with their Application to the first Principles of the fluxionary Calculus. By Mr. Marrat.

$\mathbf{R}$

Ario denotes the relation which two quantities bear to each other.

The two quantities must be of the same kind, otherwise no comparison can be made between them.

The measure of a ratio is obtained by considering, what part, or parts, one term of the ratio is of the other. Thus, let $a$ and $b$ denote the terms of a ratio, or let $\frac{a}{b}$ express any ratio; then, its measure is had by considering what part, or parts, $a$ is of $l$.

Let us denote $a$ by 6 , and $l$ by 2 , then, $\frac{6}{2}=\frac{3}{1}$, or 3 is the measure of the ratio $\frac{6}{2}$.

If $a=2$ and $b=6$, then, $\frac{2}{6}=\frac{1}{3}$; or $\frac{1}{3}$ is the measure of the ratio of $\frac{2}{6}$; and so on for other quantities. 